Radiologe 2020 60 (Suppl 1):S70-S79 https://doi.org/10.1007/s00117-020-00739-6 Published online: 14 September 2020 (c) Springer Medizin Verlag $\mathrm{GmbH}$, ein Teil von Springer Nature 2020

Check for
updates

Daniel Cantré $\cdot$ Sönke Langner ${ }^{1}$ Sebastian Kaule ${ }^{2} \cdot$ Stefan Siewert ${ }^{2}$. Klaus-Peter Schmitz ${ }^{2,3}$. André Kemmling ${ }^{4} \cdot$ Marc-André Weber $^{1}$

'Institute of Diagnostic and Interventional Radiology, Pediatric Radiology and Neuroradiology, Rostock University Medical Center, Rostock, Germany

${ }^{2}$ Institute for Implant Technology and Biomaterials e. V., associated Institution of the University of Rostock, Rostock-Warnemünde, Germany

${ }^{3}$ Institute for Biomedical Engineering, Rostock University Medical Center, Rostock-Warnemünde, Germany ${ }^{4}$ Institute of Neuroradiology, University Hospital Luebeck, Luebeck, Germany

\title{
Three-dimensional imaging and three-dimensional printing for plastic preparation of medical interventions
}

allows for precise preprocedural sizing and positioning of the implant, and is routinely performed in planning of transcatheter aortic valve implantation procedures (TAVI) [34]. However, the presentation of virtual $3 \mathrm{D}$ reconstructions on 2D displays is sometimes regarded as a limiting factor, especially for persons used to haptic feedback, i.e., surgeons [22]. Augmented reality and virtual reality are emerging promising technologies to further the potentials of 3D imaging; however, these are outside of the scope of this article [37].

\section{Medical three-dimensional printing is a novel technology closely related to diagnostic imaging}

Three-dimensional printing or, more precisely, additive manufacturing, was introduced in the 1980s [6]. The potential for life sciences was quickly recognized and printing of the first medical image-derived anatomic models started in the early 1990s [19]. Over the past decade, the market share of 3D printers began to rise exponentially, and medical $3 \mathrm{D}$ printing is being evaluated in many medical disciplines [5]. A lot of different techniques and materials for creating 3D objects from virtual 3D models have been developed in the meantime. A short overview of the most relevant technologies in medical $3 \mathrm{D}$ printing is provided in - Table 1.

Three-dimensional imaging proved to be an excellent source of data for $3 \mathrm{D}$ printing [22]. As experts in virtual 3D image reconstruction, radiologists may transfer their existing work to a $3 \mathrm{D}$ printer to produce individualized models [12]. There are many possible applications for $3 \mathrm{D}$ printing in medical education, research, and patient care, ranging from coarse anatomic models sufficient for patient education, to precise models for procedural training and patient-specific models for preprocedural simulation of complex interventions, to the additive manufacturing of medical products such as surgical guides and implants. Albeit different in nature, the corresponding printing results all share the purpose of aiding preparation or execution of medical interventions.

Many 3D printers may be operated rather intuitively; however, expertise is needed to achieve reliable and reproducible results [3]. A subgroup of $3 \mathrm{D}$ printers have become an affordable on-site technology. Albeit somewhat arbitrarily, 3D printers can be categorized into entry-level, hobbyist, enthusiast, professional, and industrial quality. Hardware investment for printers using fused deposition modelling (FDM) 


\begin{tabular}{|c|c|c|c|c|}
\hline $\begin{array}{l}\text { 3D print- } \\
\text { ing } \\
\text { method }\end{array}$ & Principle & Pros & Cons & Investment \\
\hline $\begin{array}{l}\text { Fused de- } \\
\text { position } \\
\text { modelling } \\
\text { (FDM) }\end{array}$ & $\begin{array}{l}\text { Material extrusion: } \\
\text { filaments of thermic } \\
\text { plastic on spools are } \\
\text { heated and extruded in } \\
\text { multiple layers through } \\
\text { a nozzle }\end{array}$ & $\begin{array}{l}\text { Cheap } \\
\text { Many different materials } \\
\text { PLA biocompatible } \\
\text { Printing two materials (e.g., two } \\
\text { colors or water-soluble support } \\
\text { material) }\end{array}$ & $\begin{array}{l}\text { Needs printed support material } \\
\text { Nozzle size limits spatial resolution } \\
\text { Visible layering } \\
\text { Reduced thermic resistance }\end{array}$ & $\begin{array}{l}\text { Printers from } \sim 150 € \text { (entry } \\
\text { level) } \\
\text { Professional } \sim 1000 € \\
\text { Material } 20-80 € / \mathrm{kg} \\
\text { Price of sample } \mathrm{e}^{\mathrm{a}} \text { in PLA: } 13.17 €\end{array}$ \\
\hline $\begin{array}{l}\text { Stereo- } \\
\text { lithography } \\
\text { (SLA) }\end{array}$ & $\begin{array}{l}\text { Photopolymerization: } \\
\text { liquid photopolymers } \\
\text { are polymerized layer } \\
\text { by layer through laser } \\
\text { light }\end{array}$ & $\begin{array}{l}\text { High spatial resolution } \\
\text { High surface quality } \\
\text { Thin structures } \\
\text { Great material choice }\end{array}$ & $\begin{array}{l}\text { Only one kind of material per } \\
\text { model } \\
\text { Support structures of same mate- } \\
\text { rial } \\
\text { Susceptible to UV light }\end{array}$ & $\begin{array}{l}\text { Printers from } \sim 230 € \text { (entry } \\
\text { level) } \\
\text { Professional } \sim 1500-3000 € \\
\text { Material } 60-250 € / \mathrm{kg} \\
\text { Price of sample } \mathrm{a}^{\mathrm{a}} \text { in standard } \\
\text { resin: } 28.16 €\end{array}$ \\
\hline $\begin{array}{l}\text { Multijet } \\
\text { printing } \\
\text { (MJP) }\end{array}$ & $\begin{array}{l}\text { Material jetting: } \\
\text { a printer head jets } \\
\text { material or multiple } \\
\text { materials in layers, ana- } \\
\text { logue to inkjet printers }\end{array}$ & $\begin{array}{l}\text { High spatial resolution } \\
\text { High surface quality } \\
\text { Blending/mixing of materials } \\
\text { Soluble or melting support mate- } \\
\text { rial } \\
\text { Freedom of part geometry } \\
\text { Printing of assembly groups in one } \\
\text { (e.g., ball bearing) }\end{array}$ & $\begin{array}{l}\text { Expensive } \\
\text { Material shrinking ( 1\%) }\end{array}$ & $\begin{array}{l}\text { Printers starting at } \sim 50,000 € \\
\text { Material } \sim 200 € / \mathrm{kg} \\
\text { Price of sample } \mathrm{e}^{\mathrm{a}} \text { in multicolor: } \\
36.82 €\end{array}$ \\
\hline $\begin{array}{l}\text { Binder } \\
\text { jetting }\end{array}$ & $\begin{array}{l}\text { Powder bed fusion: } \\
\text { inkjet-like printer head } \\
\text { applies a liquid binding } \\
\text { adhesive agent to } \\
\text { layers of powdered } \\
\text { material }\end{array}$ & $\begin{array}{l}\text { Fast } \\
\text { Full colored, solid parts } \\
\text { No printed support structures } \\
\text { needed } \\
\text { Freedom of part geometry }\end{array}$ & $\begin{array}{l}\text { Less mechanical endurance } \\
\text { Handling of powdered material } \\
\text { Excess material in printer bed only } \\
\text { partly reusable }\end{array}$ & $\begin{array}{l}\text { Printers starting at } \sim 50,000 € \\
\text { Leasing alternatively available } \\
\text { Price of sample }{ }^{\mathrm{a}} \text { in Nylon: } \\
22.40 €\end{array}$ \\
\hline $\begin{array}{l}\text { Selective } \\
\text { laser sin- } \\
\text { tering/ } \\
\text { molding } \\
\text { (SLS/SLM) }\end{array}$ & $\begin{array}{l}\text { Powder bed fusion: } \\
\text { sintering or molding } \\
\text { layers of granular mate- } \\
\text { rial in material bed by } \\
\text { laser }\end{array}$ & $\begin{array}{l}\text { Many materials, from plastics to } \\
\text { noble metals } \\
\text { Good mechanical properties of } \\
\text { parts (especially metals) } \\
\text { No printed support structures } \\
\text { needed } \\
\text { Freedom of part geometry }\end{array}$ & $\begin{array}{l}\text { Expensive } \\
\text { Thermal strain with risk of deforma- } \\
\text { tion } \\
\text { Coarse surfaces, metals need fur- } \\
\text { ther machining } \\
\text { Handling of granular or powdered } \\
\text { material } \\
\text { Excess material in printer bed usu- } \\
\text { ally not reusable }\end{array}$ & $\begin{array}{l}\text { Printers starting at } \sim 10,000 € \\
\text { (plastics) } \\
\text { Price of sample }{ }^{\mathrm{a}} \text { in flexible } \\
\text { plastic: } 56.91 € \\
\text { Printers } \sim 80,000 € \text { to } \\
>250,000 € \text { (metals) } \\
\text { Price of sample in aluminum: } \\
183.54 €\end{array}$ \\
\hline
\end{tabular}

or stereolithography (SLA) technology starts in the range of only a few hundred euros and material prizes start as low as $20 €$ per $\mathrm{kg}$ (FDM filaments) when including entry-level machines (• Table 1 ). Printers of the seemingly more appropriate enthusiast or professional categories start at a few thousand euros. With moderate hardware investment and material costs, little need for laboratory space, already great and growing choice of materials, and spatial resolutions down to the low two- or even one-digit micrometer range, SLA printers have become quite popular and are used in many medical 3D printing laboratories. At the other end of the spectrum, industrialquality printers reach the price range of several hundred thousand euros. They also come with higher operating costs and more challenging logistics.

For the production of classified medical products, i.e., surgical guides and implants, radiologists usually need merely provide exquisite $3 \mathrm{D}$-source imaging data, while postprocessing and computer-aided design (CAD) construction, as well as manufacturing, is performed by engineers. However, in light of an already existing demand for printing of anatomic models for research and education and with on-site printing facilities for medical products on the horizon, radiological expertise would seem highly valuable for on-site 3D printing laboratories.
This article addresses basic requirements and considerations for an onsite $3 \mathrm{D}$ printing laboratory for anatomic models, explains an exemplary SLA $3 \mathrm{D}$ printing workflow, and introduces some exemplary possibilities of individualized medical 3D printing. These steps have the intention of providing patients with top-level precision medicine and personalized therapy.

\section{Requirements}

Basic requirements for a $3 \mathrm{D}$ printing laboratory start with access to suitable 3D imaging data. Appropriate imaging parameters have been published by the Radiological Society of North Amer- 
Radiologe 2020 - 60 (Suppl 1):S70-S79 https://doi.org/10.1007/s00117-020-00739-6

(c) Springer Medizin Verlag GmbH, ein Teil von Springer Nature 2020

D. Cantré · S. Langner · S. Kaule · S. Siewert · K.-P. Schmitz · A. Kemmling · M.-A. Weber

\section{Three-dimensional imaging and three-dimensional printing for plastic preparation of medical interventions}

\section{Abstract}

Three-dimensional (3D) imaging has been available for nearly four decades and is regarded as state of the art for visualization of anatomy and pathology and for procedure planning in many clinical fields. Together with $3 \mathrm{D}$ image reconstructions in the form of rendered virtual 3D models, it has helped to better perceive complex anatomic and pathologic relations, improved preprocedural measuring and sizing of implants, and nowadays enables even photorealistic quality. However, presentation on 2D displays limits the 3D experience. Novel 3D printing technologies can transfer virtual anatomic models into true 3D space and produce both patient-specific models and medical devices constructed by computer-aided design. Individualized anatomic models hold great potential for medical and patient education, research, device development and testing, procedure training, preoperative planning, and fabrication of individualized instruments and implants. Hand in hand with 3D imaging, medical 3D printing has started to revolutionize medicine in certain fields and new applications are developed and introduced regularly. The demand for medical 3D printing will likely continue to rise, as it is a promising tool for plastic preparation of medical interventions. However, there is ongoing debate on the appropriateness of medical 3D printing and further research on its efficiency is needed. As experts in 3D imaging, radiologists are not only capable of advising on adequate imaging parameters, but should also become adept in 3D printing to participate in on-site 3D printing facilities and randomized controlled trials on the topic, thus contributing to improving patient outcomes via personalized medicine through patientspecific preparation of medical interventions.

\section{Keywords}

Computer-aided design - Stereolithography . Radiologists · Quality control · Prostheses and implants

\section{Dreidimensionale Bildgebung und 3D-Druck zur plastischen Vorbereitung medizinischer Eingriffe}

\section{Zusammenfassung}

Die dreidimensionale (3D) Bildgebung steht seit fast vier Jahrzehnten zur Verfügung und gilt als State of the Art für die Visualisierung von Anatomie und Pathologie sowie für die Therapieplanung in vielen klinischen Bereichen. Zusammen mit 3D-Bildrekonstruktionen in Form von gerenderten virtuellen 3D-Modellen hat sie dazu beigetragen, komplexe anatomische und pathologische Zusammenhänge besser zu verstehen und die präprozedurale Vermessung und Größenbestimmung von Implantaten zu verbessern. Heute kann dabei sogar fotorealistische Bildqualität erreicht werden. Die Betrachtung auf 2D-Displays schränkt jedoch die 3D-Perzeption ein. Neuartige 3D-Drucktechnologien können virtuelle anatomische Modelle in den echten 3D-Raum übertragen und erlauben die Herstellung sowohl patientenspezifischer Modelle als auch mittels CAD (",omputer- aided design") konstruierter medizinischer Geräte. Individualisierte anatomische Modelle bergen ein großes Potenzial für die medizinische Lehre und Forschung, Patientenaufklärung, Geräteentwicklung und -prüfung, für Operationskurse, präoperative Planung und Herstellung individualisierter Instrumente und Implantate. Zusammen mit der 3D-Bildgebung hat der medizinische 3DDruck begonnen, die Medizin in bestimmten Bereichen zu revolutionieren, und es werden regelmäßig neue Anwendungen entwickelt und eingeführt. Die Nachfrage nach medizinischem 3D-Druck als ein vielversprechendes Werkzeug für die plastische Vorbereitung von medizinischen Eingriffen wird wahrscheinlich noch steigen. Andererseits wird in der wissenschaftlichen Debatte kritisch hinterfragt, wann medizinischer 3D-Druck angemessen ist, und zur Beurteilung der
Effizienz des Verfahrens sind weitere Studien erforderlich. Als Experten auf dem Gebiet der 3D-Bildgebung können Radiologen nicht nur zu adäquaten Bildgebungsparametern beraten und optimale 3D-Bilddaten liefern. Vielmehr sollten sie sich auch selbst mit dem 3D-Druck vertraut machen, um als Partner an lokalen 3D-Druck-Enrichtungen und an randomisierten kontrollierten Studien zu diesem Thema teilzunehmen und so dazu beizutragen, die personalisierte Medizin mittels patientenspezifischer Vorbereitung medizinischer Eingriffe voranzubringen.

\section{Schlüsselwörter}

Computer-aided Design · Stereolithographie . Radiologen · Qualitätskontrolle · Prothesen und Implantate ica (RSNA) 3D Printing Special Interest Group [8].

For segmentation and rendering of anatomic details of interest, many different software solutions are available to fit specific requirements or personal preferences. Recent research in 3D segmentation and rendering focuses on automation, e.g., using artificial intelligence [9]. However, to produce anatomically precise and reproducible models of a patient's individual anatomy, it is still important to confirm correct results in every step of the 3D printing process, i.e., to implement quality control mechanisms, which requires expertise of specialized personnel [23].

Careful consideration is necessary with regards to the intended use of the $3 \mathrm{D}$ printed parts. If they classify as medical products there are complex legal and safety issues [33]. For additive manufacturing of surgical instruments, devices, and implants, which qualify as class II and class III medical products, the whole manufacturing process has to be certified, e.g., Food and Drug Administration (FDA) approved or CE marked (other local regulations may apply), including all software used [29]. More and more clinical imaging software solutions, which must be certified for use in patient care per se, offer extensions 
for exporting 3D printable file formats. Usually, standard triangulation language (STL) files are created [12]. One has to be aware that with the creation and export of a 3D printable file, the clinical imaging software's range of validity ends and the further workflow may not be covered by the certification. To the best of the authors' knowledge, there is currently only one FDA-approved and CE-marked software solution for further processing of STL files commercially available for end users [16]. As an alternative option in education and research there is welldocumented software distributed as open source, with vibrant user communities as sources of information and help (good overviews have been published by Virzì et al. [39] and Hodgdon et al. [20]).

Choosing the right $3 \mathrm{D}$ printer hardware for a printing laboratory can be a challenging task. Many details have to be considered, such as the size of the models, the type, quality, and cost of materials, spatial resolution, the possibility of printing multiple materials or different colors in one model, and available laboratory space among other resources. There is definitely not a "one-stop shop" solution, and with multiple different printing techniques, vendors, and models on the market and frequent emergence of new products, one might fear misinvestment. An in-depth discussion of different printing techniques and properties of the diverse materials is out of the scope of this article. - Table 1 provides an overview over the main printing techniques and others have published helpful information regarding material choice [15]. Helpful sources of information are also provided by local academic societies in the form of scientific meetings and handson courses [4], the 3D Printing Special Interest Group of the RSNA with online resources and publication of guidelines [8], as well as the pertinent journal $3 D$ printing in Medicine [40]. On the other hand, both industrial partners and academic (non-medical) 3D printing core facilities provide $3 \mathrm{D}$ printing as a service, which is an option with minimal investment for getting projects started.

Depending on the chosen printing technology, specific occupational health and environmental safety issues need to be considered. Storing, handling, and disposing of noxious printing materials as well as supplementary chemicals and their vapors may be detrimental both for the personnel and the environment. In SLA printing, for example, there is a risk of formation of resin aerosols and volatile organic compounds that can be addressed by sufficient ventilation [36]. The handling of metal powders and inert gases in SLM on the other hand is far more complex. Excess material and debris of the production process might classify as hazardous waste. Recycling of unused materials is not an option in many cases for quality reasons [18]. Thus, the extent and quality of $3 \mathrm{D}$ printing should, in the authors' opinion, be monitored to avoid excess printing, particularly if the product is intentionally short lived or of questionable appropriateness, bearing the likelihood of forming the waste of tomorrow without justification through an increased quality of patient care.

Three-dimensional printing can be expensive and, until recently, reimbursement for 3D printing of anatomic models was basically nonexistent. In 2018, the American College of Radiology (ACR) was able to take a step forward when the American Medical Association (AMA) accepted their proposal for temporary "current procedural terminology" codes (i.e., category III CPT codes), allowing for reimbursement of individualized 3Dprinted anatomic models and surgical instruments for a preliminary period of 5 years starting in 2019 [35]. For permanent reimbursement of 3D printing applications to become established around the world, there is a need for more randomized controlled trials (RCT) to elucidate their effectiveness. To date, results are somewhat inconsistent, e.g., in different fields of surgery. Recent meta-analyses of RCT on treatment of tibial plateau and pilon fractures showed significant advantages of 3D printing-assisted surgery in terms of operation time, blood loss, postoperative functional score, postoperative pain, rate of excellent and good outcome, and rate of anatomic reduction compared to conventional techniques [2, 41]. On the other hand, a group of Swiss dental surgeons who conducted an RCT comparing conventional versus computer-aided planning and 3D printing-assisted placement of implants seems hesitant as to whether the observed gain in accuracy and precision would justify the rise of $20-31 \%$ in overall economic costs $[31,32]$.

\section{Exemplary three-dimensional printing workflow}

The steps it takes to manufacture a 3Dprinted object from 3D imaging data are very similar for different applications and printing techniques. These include (a) production of applicable 3D imaging data, (b) segmentation of anatomic regions of interest, (c) generation of a 3D printable file (STL), (d) postprocessing of the STL file to create the model, (e) transfer of the designed model to the printer and printing, (f) cleaning and curing the printed model, and, facultatively, (g) further processing of the model (e.g., grinding, drilling, additional conventional machining).

\section{Accurate anatomic three- dimensional models can be printed on-site by stereolithography}

A detailed description of the authors' SLA printing workflow for hollow 3D models of intracranial arteries that are used for individualized simulation of intracranial vascular interventions, e.g., stent-assisted coiling of intracranial aneurysms, is presented exemplarily (• Figs. 1, 2, 3, 4 and 5). SLA printing takes roughly one day from a $3 \mathrm{D}$ image stack to the final 3D-printed object. The first task is defining, segmenting, and rendering the anatomic structures of interest from the imaging data. For complex models including different anatomic structures, each part must be segmented individually. - Fig. 1 shows segmentation of the vertebrobasilar arteries in a patient with an aneurysm of the intradural segment of the left vertebral artery using contrastenhanced CT angiography as the imaging source and the corresponding volume rendering result. It is important to check for accuracy of the segmentation results by comparison with the source images, e.g., using mask overlay in multiplanar reformations. The segmented 

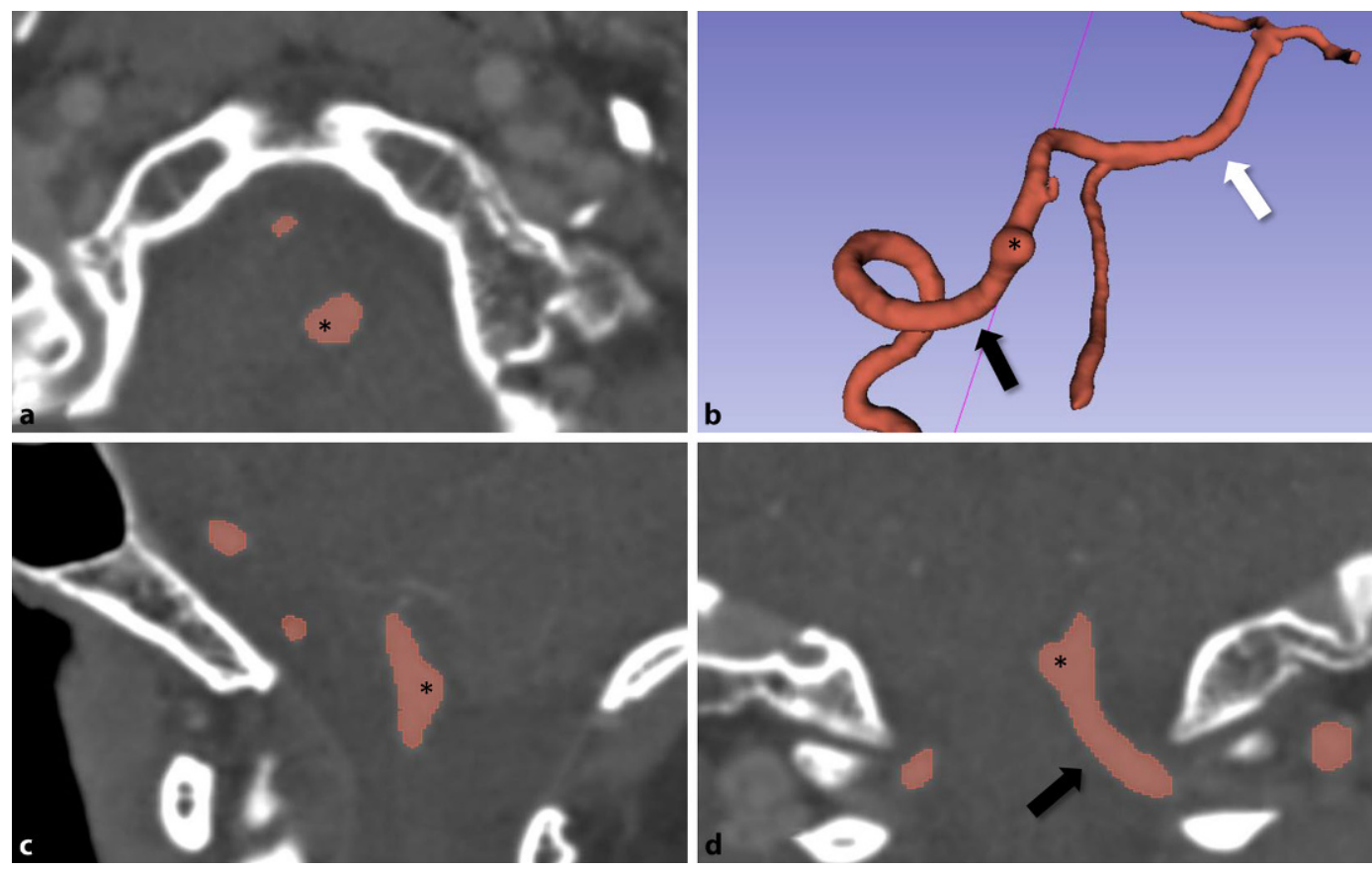

Fig. $1<$ Multiplanar reconstruction of a contrast-enhanced CT angiography in a axial, c sagittal, and $\mathbf{d}$ coronal views is used to segment the vertebrobasilar arteries in a patient with an intradural aneurysm (asterisk) of the left vertebral artery (black arrow) using a combination of filters in 3D slicer (slicer.org). The rendered virtual model (b) is then exported as a standard triangulation language file (white arrow basilar artery)
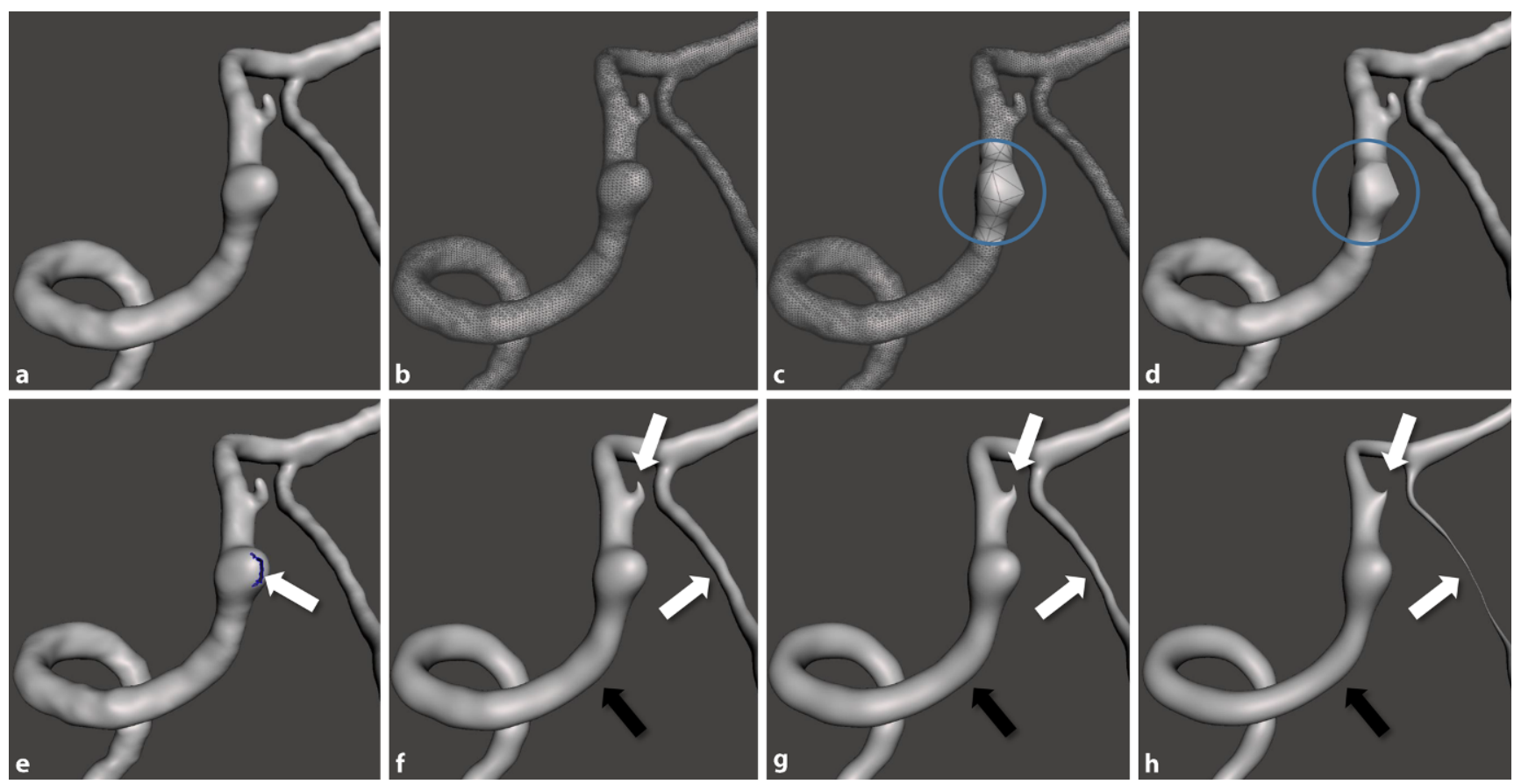

Fig. $2 \Delta$ Pitfalls in postprocessing of the primary standard triangulation language file (a). b Check for integrity of the triangle mesh. Defects (white arrow in e) must be repaired. If mesh density is set too low (blue circles in c and d), structures get sharp edges and lose form. Overuse of smoothing filters ( $\mathbf{f}-\mathbf{h})$ not only flattens coarse surfaces (black arrows), but deforms and reduces thin details (white arrows)

parts are then converted into an STL file, where surfaces are represented as meshes of small triangles. STL files usually need further processing according to the intended use of the model. In the presented example for printing hollow models of intracranial vasculature, the segmented vessels represent a negative for the model to be designed. It is important not to erroneously alter the virtual model, e.g., by too much smoothing, and to check the sizing and integrity of the mesh (• Fig. 2). For hollow models an outer hull is CAD constructed. By sub- tracting the file representing the source vessel from this hull, the model receives a lumen identical to the original vessel (• Fig.3). Further modifications are possible, such as attachment of connectors to fit the tubing of a flow model simulator. Depending on the required anatomic 


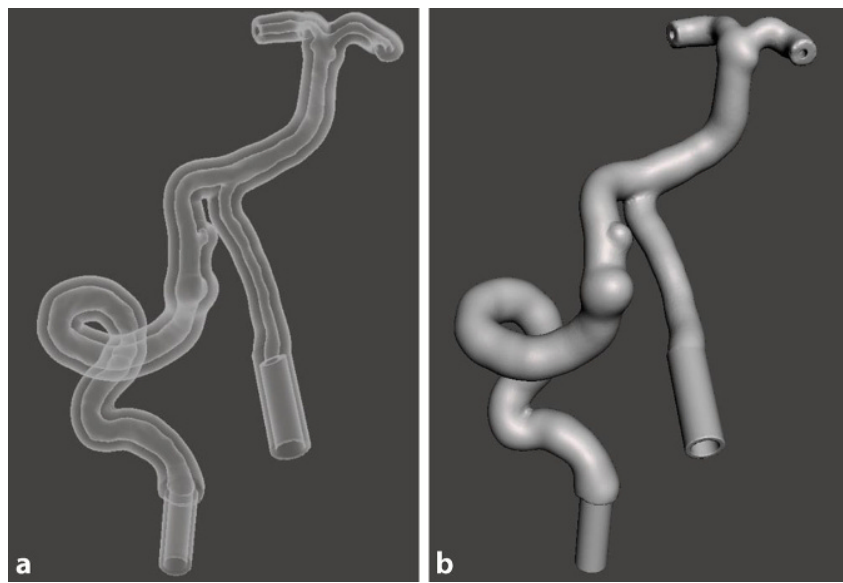

Fig. $3 \Delta$ The final printable standard triangulation language (STL) model. a Transparent view allows for verification of vessel lumen patency and correct positioning of the connectors. The model was computer-aided design-constructed by expanding a copy of the source model file for $3 \mathrm{~mm}$ in all spatial directions to create the hull (surface rendering of b) and subtraction of the source STL file to "cut out" the vessel lumen

detail, complexity, and size of the model, anything from about one to a few hours may be needed for the construction of the virtual model.

In the next step, the finalized virtual model is transferred to the printer's software. Here, it is virtually placed on the building platform in a way that allows for sufficient stability, correct positioning of support structures, and easy drainage of excess liquid resin (- Fig. 4). Again, it must be ensured that the size of the model is not accidentally altered. The most time-consuming part is the $3 \mathrm{D}$ printing itself, because the process of stepby-step photopolymerization of layers of resin only a few micrometers thin takes several hours. The main factor with respect to printing time is the height of the model. Typically, printing may be performed overnight. However, when printing a complex model with uncertain mechanical properties for the first time, it may be wise to monitor the printing process closely to prevent failure.

Once successfully printed, the model is carefully removed from the building platform and cleaned of excess liquid resin. The support structures are removed (- Fig. 5) and the model is exposed to ultraviolet (UV) light in a dedicated UV light chamber for another 60-120 min to harden the material. Further processing such as grinding for better transparency of clear resins may need more time. If intended for re- search or preparation of therapeutic interventions, models should be tested for accuracy and reproducibility. If specific regulations do not exist, this may be done by applying standardized measurements of representative features, e.g., with a sliding caliper, and comparison to measurements acquired in the source 3D imaging study [16]. Hollow vascular models can be re-scanned with a 3D imaging modality of choice. The result can then be compared with the source imaging by overlay of the images and calculation of the difference [23]. Differences of less than $0.5-1 \mathrm{~mm}$ are achievable, comparable to the accuracy of measurements in clinical diagnostic imaging (• Fig. 6).

\section{Exemplary applications of medical three-dimensional printing}

Based on the type of printing result and its intended use, 3D printing in medicine can be categorized in to three main groups.

For 3D printing of surgical implants and devices, the highest quality standards apply, identical to competing conventional manufacturing processes that usually cannot be met in a bedside setting [33]. Examples are metal orthopedic implants for hip, knee, and spinal surgery manufactured by selective laser melting (SLM). The benefits of using 3D print- ing in this category are often more on the side of productivity and cost advantages as well as the possibility of manufacturing complex geometries that are difficult to achieve with conventional machining alone. SLM results require considerable postprocessing, including additional conventional machining, e.g., for cutting screw threads.

Three-dimensionally printed products for temporary contact with patients form the second group. As an example of external aids, the production of 3Dprinted individualized casts was shown to improve comfort and satisfaction of patients with radial fractures, with effective healing and without cast complications [7]. The authors used SLA printing for their prototypes, but emphasize that their casts, CAD-constructed from 3D imaging data of a photometric surface scanner, could theoretically be printed with arbitrary $3 \mathrm{D}$ printers and printing methods on site, provided requirements for material properties are met [24]. There are also commercially available applications in orthopedic surgery which promise to improve implant positioning and reduce operative time, intraoperative blood loss, and length of hospital stay through image-derived 3D printing of individualized instruments and guides, e.g., in knee and shoulder arthroplasty. For patient-specific instrumentation in total knee arthroplasty, surgical guides are adjusted to the patient's individual anatomy by the vendors' engineers, using $\mathrm{CAD}$ in combination with preoperatively acquired 3D CT images. These guides are 3D printed, sterilized, and then used intraoperatively to define the osteotomy planes for precise placement of the chosen endoprosthesis parts. However, there is ongoing debate on the efficacy. Some groups show advantages of patient-specific instrumentation for alignment of some but not all prosthesis components as well as for reduction of operative time and perioperative blood loss, but no difference in the length of hospital stay [17]. Contradictorily, other groups report that patient-specific instrumentation does not result in clinically meaningful improvement in alignment, fewer outliers, or better early 


\section{Review}
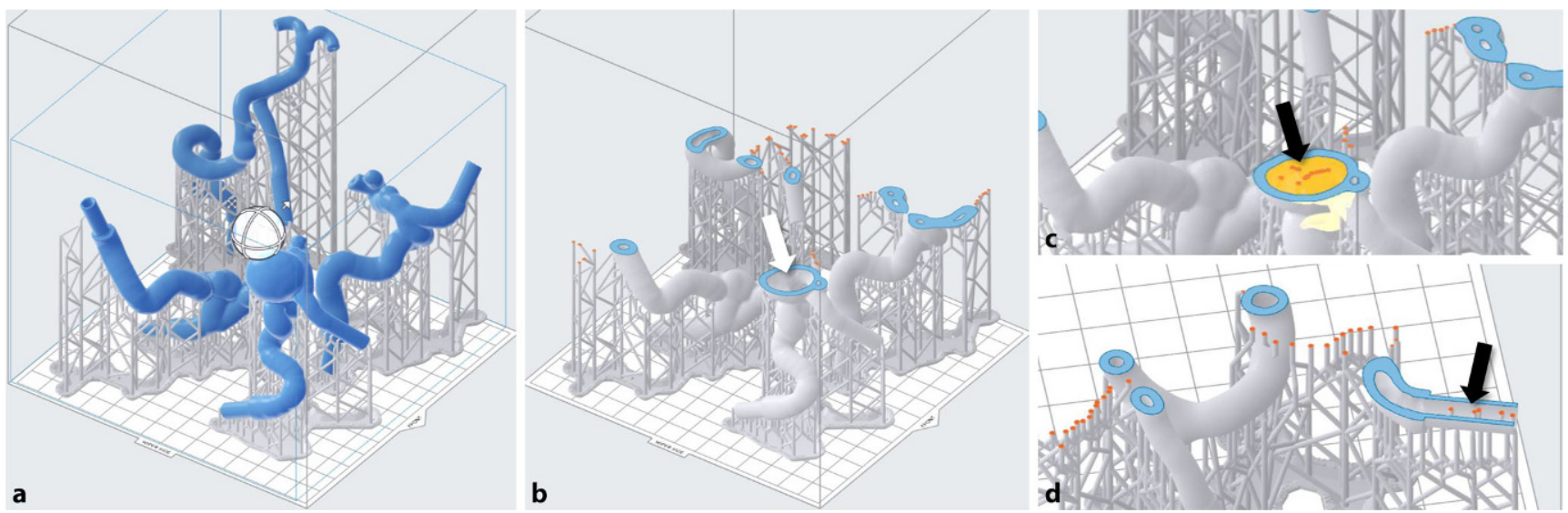

Fig. 4 \ Printing preparation with PreForm (www.formlabs.com). a Several standard triangulation language model files (blue) are placed on the virtual building platform and support structures ( $g r e y)$ are positioned. b Verification of empty model lumen. No structures are allowed inside the model lumen (white arrow). Beware of plungers (yellow area in c), which prevent drainage of excess resin and intraluminal support structures (d blackarrows) that may obstruct the model
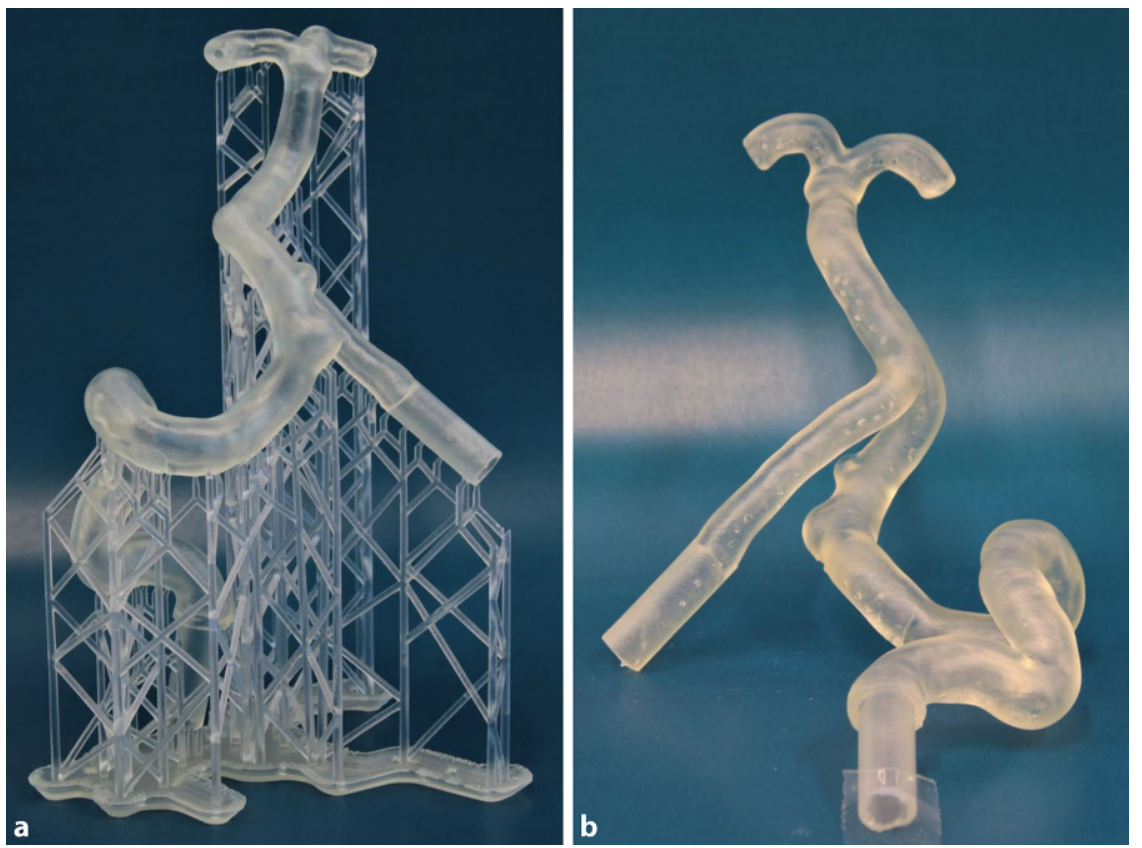

Fig. $5 \Delta$ Successfully three-dimensionally printed hollow vascular model. The support structures in a are carefully removed with pliers. After ultraviolet light curing, the vascular model (b) is ready for use

patient-reported outcome measures, and it does not reduce operation time [21].

Given the requisite industrial background and legal considerations in the production and distribution of medical products for permanent or temporary use in patients, widespread on-site manufacturing of metal implants or plastic guides is not yet implemented and radiologists need merely provide ideal 3D-source imaging, as described above. However, there is some overlap with onsite facilities, for example in the plan-
Anatomic models are a good starting point for on-site threedimensional printing laboratories

Three-dimensional printing of anatomic models represents the third group and has a great variety of applications. In visualization for patient and medical education, models do not necessarily qualify as medical products. Therefore, no certification and industrial standard quality control is needed. This may be a good starting point for $3 \mathrm{D}$ printing projects with relatively low barriers. Apparently, 3D printing of anatomic models has become so common that even laymen with access to homeuser $3 \mathrm{D}$ printing equipment are able to produce them. Recently, one of the authors' elderly patients brought a model of his own intracranial vasculature to the preprocedural workup for endovascular treatment of his dural arteriovenous fistula - his son had printed it from a timeof-flight MRI angiography using an FDM printer (• Fig. 7).

If anatomic models are used for aiding in diagnosis, for procedure planning or procedural training, for research, for preclinical device testing, or device development, higher quality requirements usually apply, as mentioned above. Threedimensional models for diagnosis and procedure planning have been proven to impact upon the surgeon's decision regarding operative approach or technique. In an international multicenter study, Valverde et al. observed that addi- 

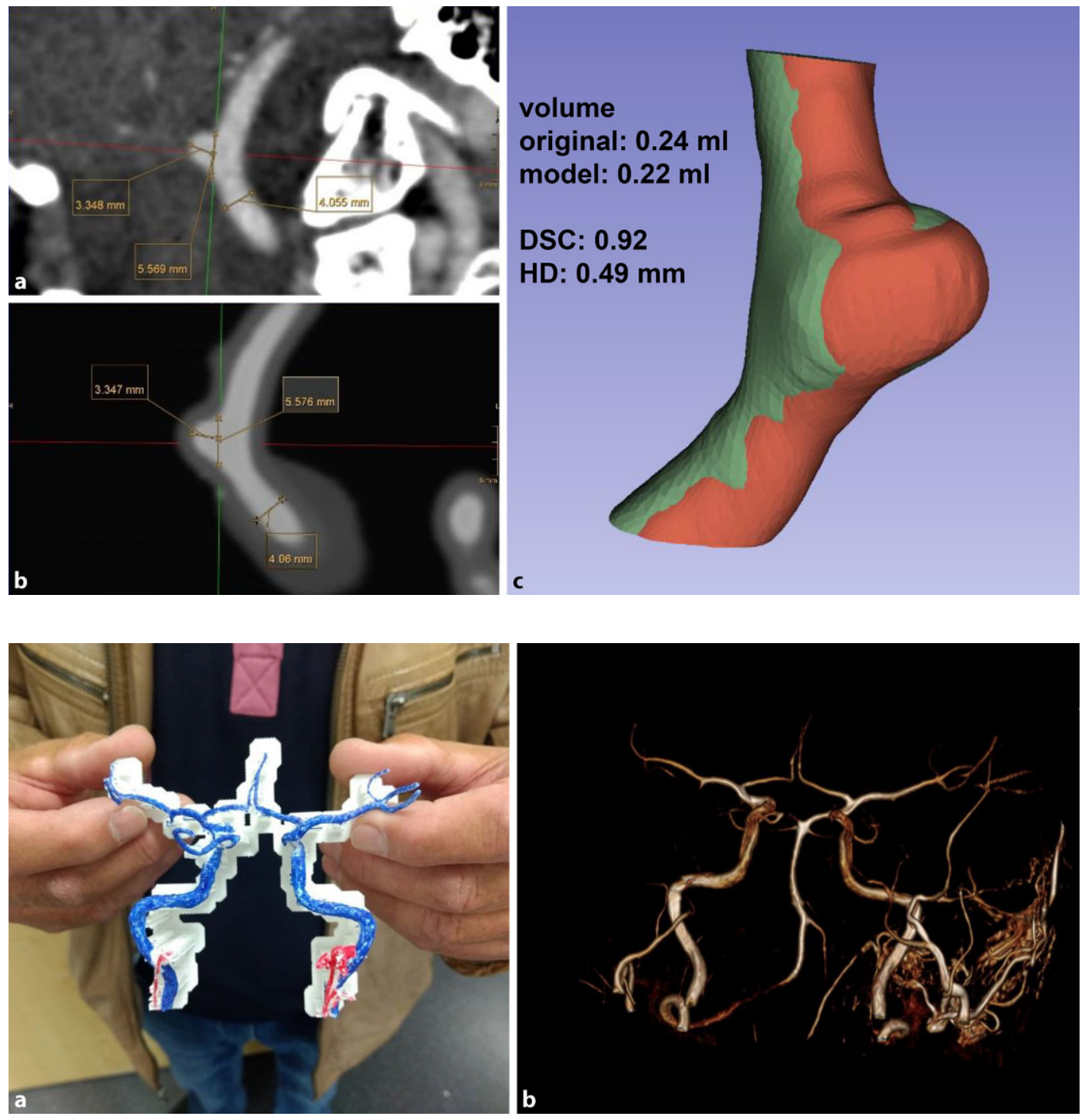

Fig. $6<$ Quality control of hollow vascular models. Comparative measurements in a the source CT angiography data and $\mathbf{b}$ a CT scan of the derived threedimensionally printed model, filled with iodinated contrast. c After segmentation of the model's contrast-filled lumen (brown) it can be compared to the original vessel segmentation (green) shown as an overlay. A Hausdorff distance of less than $0.5 \mathrm{~mm}$ and a Dice similarity coefficient of $>0.9$ show high similarity of the two segmentations

Fig. $7 \Delta$ a A layman's home-printed three-dimensional (3D) model of his intracranial vessels, produced using a fused deposition modelling printer and hand coloring (arteries blue, veins red, support structures undyed). The source image was a time-of-flight MRI angiography (exemplary volume rendering in $\mathbf{b}$ ). Only vague depiction of the true extent of pathology, a complex left-sided dural arteriovenous fistula, was possible with the 3D model

tional 3D printing of anatomic models for surgical planning of complex congenital heart defects changed the surgical decision in nearly $50 \%$ of cases as compared to conventional planning by multimodality 3D imaging (CT, MRI, and 3D echocardiography) with virtual 3D image reconstruction by imaging specialists [38]. Goo et al. conducted an in-depth comparison between different medical imaging-derived $3 \mathrm{D}$ visualization techniques and $3 \mathrm{D}$ printing for congenital heart disease and also point out that the soughtafter tangibility of printed $3 \mathrm{D}$ models is unparalleled by other methods [18]. In line with this, the authors wish to em- phasize that medical 3D printing applications should always be compared to expertly performed virtual $3 \mathrm{D}$ reconstruction, presentation, and procedure planning by imaging specialists.

In the authors' center, 3D printing of hollow vessel models of intracranial arteries has been established, as described above in detail. The printed vascular models are connected to a mobile flow simulator (www.flowmodda.com) that is easily transportable to different angiography suites. Using standard angiographic equipment, the treatment of different pathologies of intracranial vasculature can already be simulated for educational purposes (• Fig. 8). With individualized, patient-specific models, it is possible to simulate challenging intracranial interventions, e.g., coiling of complex intracranial aneurysms [14]. The authors are on the way to implementing quality control mechanisms that will allow further use of these models for development and preclinical testing of novel endovascular devices.

\section{Outlook}

Three-dimensional printing has already greatly affected medicine and will likely become a game-changer in a rising num- 

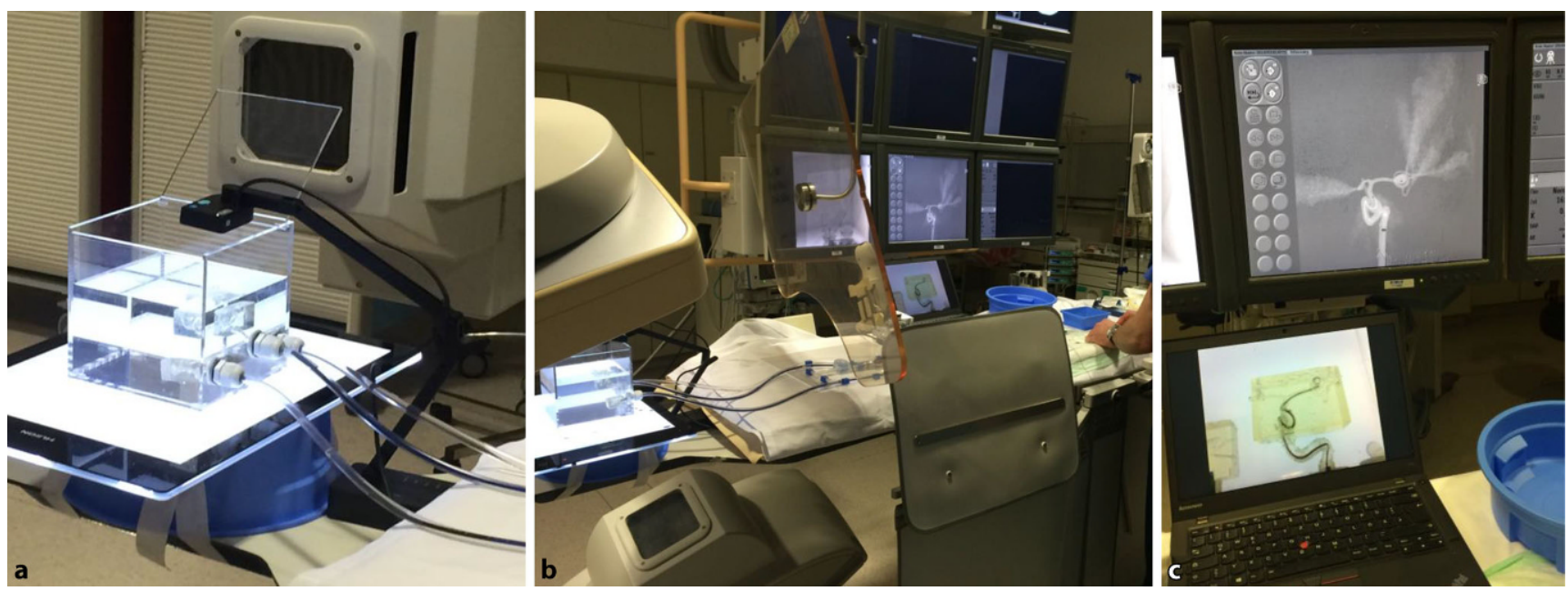

Fig. $8 \Delta$ Exemplary setup in the angiography suite for training of endovascular treatment of intracranial aneurysms (Flow Models for Deployment of Devices in Aneurysms, FlowModda, www.flowmodda.com). a The three-dimensional (3D) model is connected to a fluid circulation system and immersed in water inside the transparent box representing a patient's head. $\mathbf{b}$ The model is accessed through silicone tubing with standard angiographic equipment, simulating transfemoral approach.c $\mathrm{A}$ transparent 3D model allows for parallel imaging by angiography (upper flatscreen monitor) and USB camera (laptop screen)

ber of medical fields as well as for vendors of medical products. Clinical radiology has an important role in medical 3D printing, as it provides the appropriate source imaging data. Radiologists themselves will likely benefit from $3 \mathrm{D}$ printing through novel possibilities of education, procedural training, and individualized simulation of interventions, as well as from development of novel implants and devices for endovascular minimally invasive treatment to provide precision personalized medicine. However, the efficacy of many medical 3D printing applications is still of debate and requires further investigation. Looking at the Gartner Hype Cycle for emerging technologies, the peak of inflated expectations still lies before us, and a trough of disillusionment will inevitably follow [1]. On the other hand, this means that the demand for medical 3D printing will very likely keep growing throughout the current decade. Expert personnel with in-depth knowledge of 3D printing techniques will therefore become an invaluable human resource both for on-site printing laboratories and as advisors for external printing services.

Radiologists need to be familiar with 3D printing and should participate in local $3 \mathrm{D}$ printing laboratories, ideally in executive or advisory positions. It seems wise for radiologists to educate them- selves accordingly and join the 3D printing subspecialty groups of the different radiological societies. Three-dimensional printing is time consuming and depends on expert manpower that is not yet adequately financed around the world. Radiologists should support the efforts to establish appropriate reimbursement, as the has ACR proved possible [27]. One important option is to participate in or to initiate RCT to further elucidate the benefits and efficacy of medical 3D printing in a great variety of possible applications. Thus, radiologists may help to reach the plateau of productivity that the Gartner Hype Cycle suggests [1].

\section{Conclusions}

- Medical 3D printing has come to stay, and radiologists should acquire expertise to advise on appropriate 3D imaging and become leading experts in 3D printing laboratories.

- The 3D printing of patient-specific anatomic models is highly accurate and represents an option to prepare medical interventions with realistic haptic feedback and superior conception of spatial relations in comparison to $3 \mathrm{D}$ imaging.

- On-site 3D printing has become an affordable option, especially for education, research, procedure simulation, and treatment planning.

- For interventional radiologists, 3D printing offers novel possibilities for training and individualized preparation of interventions.

- Radiologists should initiate or participate in multicenter RCT on medical 3D printing, to elucidate the appropriateness and possibly establish adequate reimbursement of medical $3 \mathrm{D}$ printing.

\section{Corresponding address}

Dr. med. Daniel Cantré
Institute of Diagnostic and
Interventional Radiology,
Pediatric Radiology and
Neuroradiology, Rostock
University Medical Center
Ernst-Heydemann-Str. 6,
18057 Rostock, Mecklenburg
Western Pomerania, Germany
daniel.cantre@med.uni-
rostock.de

\section{Compliance with ethical guidelines}

Conflict of interest. D. Cantré, S. Langner, S. Kaule, S. Siewert, K.-P.Schmitz, A. Kemmling, and M.-A. Weber declare that they have no competing interests. 
For this article no studies with human participants or animals were performed by any of the authors. All studies performed were in accordance with the ethical standards indicated in each case.

The supplement containing this article is not sponsored by industry.

\section{References}

1. Gartner (2019) 5 trends appear on the Gartner hype cycle for emerging technologies. https://www. gartner.com/smarterwithgartner/5-trends-appear-on-the-gartner-hype-cycle-for-emergingtechnologies-2019. Accessed 15 Apr 2020

2. Bai J, Wang Y, Zhang P, Liu M, Wang P, Wang J, Liang Y (2018) Efficacy and safety of 3D print-assisted surgery for the treatment of pilon fractures: a meta-analysis of randomized controlled trials. JOrthop Surg Res 13(1):283

3. Bartel T, Rivard A, Jimenez A, Mestres CA, Müller S (2018) Medical three-dimensional printing opens up new opportunities in cardiology and cardiac surgery. Eur Heart J39(15):1246-1254

4. Buzug T, Seitz H (eds) (2019) Additive Manufacturing Meets Medicine (AMMM 2019). International Conference on 3D-Printing in Medicine. Infinite Science, Lübeck

5. Chae MP, Rozen WM, McMenamin PG, Findlay MW, Spychal RT, Hunter-Smith DJ (2015) Emerging applications of bedside 3D printing in plastic surgery. Front Surg 2:25

6. Hull CW (1984) Apparatus for production of three-dimensional objects by stereolithography $(4,575,330)$

7. Chen Y-J, Lin H, Zhang X, Huang W, Shi L, Wang D (2017) Application of 3D-printed and patientspecific cast for the treatment of distal radius fractures: initial experience. 3D Print Med 3(1):11

8. Chepelev L, Wake N, Ryan J, Althobaity W, Gupta A, Arribas E, Santiago L, Ballard DH, Wang KC, Weadock W, lonita CN, Mitsouras D, Morris J, Matsumoto J, Christensen A, Liacouras P, Rybicki FJ, Sheikh A (2018) Radiological Society of North America (RSNA) 3D printing Special Interest Group (SIG): guidelines for medical 3D printing and appropriateness for clinical scenarios. 3D Print Med. https://doi.org/10.1186/s41205-018-0030$y$

9. Duong MT, Rauschecker AM, Rudie JD, Chen P-H, Cook TS, Bryan RN, Mohan S (2019) Artificial intelligence for precision education in radiology. BrJRadiol 92(1103):20190389

10. Duran AH, Duran MN, Masood I, Maciolek LM, Hussain $\mathrm{H}$ (2019) The additional diagnostic value of the three-dimensional volume rendering imaging in routine radiology practice. Cureus 11(9):e5579

11. Eid M, de Cecco CN, Nance JW, Caruso D, Albrecht MH, Spandorfer AJ, de Santis D, VargaSzemes A, Schoepf UJ (2017) Cinematic rendering in CT: a novel, lifelike 3D visualization technique. AJR Am J Roentgenol 209(2):370-379

12. Esses SJ, Berman P, Bloom Al, Sosna J (2011) Clinical applications of physical 3D models derived from MDCT data and created by rapid prototyping. AJR Am JRoentgenol 196(6):W683-W688

13. Ferdinand FD, Heiman M, Ben-Or S, Curtain AJ, Goldman SM(2004)Three dimensional reconstruction of CT scan images to aid the cardiac surgeon. Semin Thorac Cardiovasc Surg 16(3):249-254

14. Frölich AMJ, Spallek J, Brehmer L, Buhk J-H, Krause D, Fiehler J, Kemmling A (2016) 3D printing of intracranial aneurysms using fused deposition modeling offers highly accurate replications. AJNR Am J Neuroradiol 37(1):120-124

15. Garcia J, Yang Z, Mongrain R, Leask RL, Lachapelle K (2018) 3D printing materials and their use in medical education: a review of current technology and trends for the future. BMJSTEL 4(1):27-40

16. George E, Liacouras P, Rybicki FJ, Mitsouras D (2017) Measuring and establishing the accuracy and reproducibility of 3D printed medical models. Radiographics 37(5):1424-1450

17. Gong S, Xu W, Wang R, Wang Z, Wang B, Han L, Chen $G$ (2019) Patient-specific instrumentation improved axial alignment of the femoral component, operative time and perioperative blood loss after total knee arthroplasty. Knee Surg Sports Traumatol Arthrosc 27(4):1083-1095

18. Goo HW, Park SJ, Yoo S-J (2020) Advanced medica use of three-dimensional imaging in congenital heart disease: augmented reality, mixed reality, virtual reality, and three-dimensional printing. Korean J Radiol 21(2):133-145

19. Heller M, Bauer H-K, Goetze E, Gielisch $M$ Roth KE, Drees P, Maier GS, Dorweiler B, Ghazy A, Neufurth M, Müller WEG, Schröder HC, Wang X, VahlC-F, Al-Nawas B (2016) Applications of patientspecific 3D printing in medicine. Int J Comput Dent 19(4):323-339

20. Hodgdon T, Danrad R, Patel MJ, Smith SE, Richardson ML, Ballard DH, Ali S, Trace AP, DeBenedectis CM, Zygmont ME, Lenchik L, Decker SJ (2018) Logistics of three-dimensional printing: primer for radiologists. Acad Radiol 25(1):40-51

21. Huijbregts HJTAM, Khan RJK, Sorensen E, Fick DP, Haebich S (2016) Patient-specific instrumentation does not improve radiographic alignment or clinical outcomes after total knee arthroplasty. Acta Orthop 87(4):386-394

22. Katkar RA, Taft RM, Grant GT (2018) 3D volume rendering and 3D printing (additive manufacturing). Dent Clin North Am 62 (3):393-402

23. Leng S, McGeeK, Morris J, Alexander A, Kuhlmann J, Vrieze T, McCollough CH, Matsumoto J (2017) Anatomic modeling using 3D printing: quality assurance and optimization. 3D Print Med 3(1):6

24. Lin H, Shi L, Wang D (2015) A rapid and intelligent designing technique for patient-specific and 3Dprinted orthopedic cast. 3D Print Med 2(1):4

25. Mankovich NJ, Robertson DR, Cheeseman AM (1990) Three-dimensional image display in medicine. J Digit Imaging 3(2):69-80

26. Mortele KJ, McTavish J, Ros PR (2002) Current techniques of computed tomography. Helical CT, multidetector $\mathrm{CT}$, and 3D reconstruction. Clin Liver Dis 6(1):29-52

27. Rankin TM, Wormer BA, Miller JD, Giovinco NA, AI Kassis S, Armstrong DG (2018) Image once, print thrice? Three-dimensional printing of replacement parts. Br JRadiol 91(1083):20170374

28. Remy J, Remy-Jardin M,ArtaudD, Fribourg M(1998) Multiplanarand three-dimensional reconstruction techniques in CT: impact on chest diseases. Eur Radiol 8(3):335-351

29. Ricles LM, Coburn JC, Di Prima M, Oh SS (2018) Regulating 3D-printed medical products. Sci Transl Med 10:461

30. Rogers-Vizena CR, Sporn SF, Daniels KM, Padwa BL, Weinstock P (2017) Cost-benefit analysis of threedimensional craniofacial models for Midfacial distraction: a pilot study. Cleft Palate Craniofac J 54(5):612-617

31. Schneider D, Sancho-Puchades M, Mir-Marí J, Mühlemann S, Jung R, Hämmerle C (2019) A randomized controlled clinical trial comparing conventional and computer-assisted implant planning and placement in partially edentulous patients. Part 4: accuracy of implant placement. Int JPeriodontics Restorative Dent 39(4):e111-e122

32. Schneider D, Sancho-Puchades M, Schober F, Thoma D, HämmerleC, Jung R(2019) A randomized controlled clinical trial comparing conventional and computer-assisted implant planning and placement in partially edentulous patients. Part 3: time and cost analyses. Int J Periodontics Restorative Dent 39(3):e71-e82

33. Schuh JCL, Funk KA (2019) Compilation of international standards and regulatory guidance documents for evaluation of biomaterials, medical devices, and 3-D printed and regenerative medicine products. Toxicol Pathol 47(3):344-357

34. SchwarzF, LangeP,ZinsserD, GreifM, Boekstegers $P$, Schmitz C, Reiser MF, Kupatt C, Becker HC (2014) $\mathrm{CT}$-angiography-based evaluation of the aortic annulus for prosthesis sizing in transcatheter aortic valve implantation (TAVI)-predictive value and optimal thresholds for major anatomic parameters. PLoSOne 9(8):e103481

35. Shin J, Truong QA (2018) Manufacturing better outcomes in cardiovascular intervention: 3D printing in clinical practice today. Curr Treat Options Cardio Med 20(12):95

36. Stefaniak AB, Bowers LN, Knepp AK, Luxton TP Peloquin DM, Baumann EJ, Ham JE, Wells JR, Johnson AR, LeBouf RF, Su F-C, Martin SB, Virji MA (2019) Particle and vapor emissions from vat polymerization desktop-scale 3-dimensional printers. JOccup Environ Hyg 16(8):519-531

37. Uppot RN, Laguna B, McCarthy CJ, de Novi G, Phelps A, Siegel E, Courtier J (2019) Implementing virtual and augmented reality tools for radiology education and training, communication, and clinical care. Radiology 291(3):570-580

38. Valverde I, Gomez-Ciriza G, Hussain T, SuarezMejias C, Velasco-Forte MN, Byrne N, Ordoñez A, Gonzalez-Calle A, Anderson D, Hazekamp MG, Roest AAW, Rivas-Gonzalez J, Uribe S, El-Rassi I, Simpson J, Miller O, Ruiz E, Zabala I, Mendez A, Manso B, Gallego P, Prada F, Cantinotti M, AitAli L, Merino C, Parry A, Poirier N, Greil G, Razavi R, Gomez-Cia T, Hosseinpour A-R (2017) Three-dimensional printed models for surgical planning of complex congenital heart defects: an international multicentre study. Eur J Cardiothorac Surg 52(6):1139-1148

39. Virzì A, Muller CO, Marret J-B, Mille E, Berteloot L, Grévent D, Boddaert N, Gori P, Sarnacki S, Bloch I (2019) Comprehensive review of 3D segmentation software tools for MRI usable for Pelvic surgery planning. J Digit Imaging 33(1):99-110

40. Wake N, Alexander AE, Christensen AM, Liacouras PC, Schickel M, Pietila T, Matsumoto J (2019) Creating patient-specific anatomical models for 3D printing and AR/VR: a supplement for the 2018Radiological Society of North America (RSNA) hands-on course. 3D Print Med. https://doi.org/10. 1186/s41205-019-0054-y

41. Xie L, Chen C, Zhang Y,Zheng W, Chen H, Cai L (2018) Three-dimensional printing assisted ORIF versus conventional ORIF for tibial plateau fractures: a systematic review and meta-analysis. Int J Surg 57:35-44 